\title{
Pre-Analysis Plan \\ How Do Parents Make Choices? Competitiveness and Gender
}

\author{
Jonas Tungodden \\ Department of Economics, UC Berkeley \\ jonas.tungodden@gmail.com
}

August 12, 2017

\section{Introduction}

Parents are fundamental in shaping children's outcomes Knudsen et al., 2006, Sacerdote, 2007, Sacerdote, 2010, Dohmen et al., 2011, Heckman, 2014, Fagereng et al., 2015. One key mechanism through which parents exert influence, is by making choices for their children during childhood and adolescence. Study physics or sociology? Attend academic or vocational training? Play soccer or learn the guitar? How parents make such choices may be important both for children's personality development and their long term outcomes.

In this project I study how parents make such choices for their children, and how the choices relate to children's own choices. I focus on the domain of competitiveness, and the role of child gender in parents' choices. The research is motivated by the growing literature on gender differences in competitiveness, which finds that girls are much less willing to compete than boys, and that competitiveness is strongly linked to important educational choices made in adolescence Zhang, 2013, Buser et al., 2014, Niederle, 2014.

To study parents' choices, I recruit a largely representative sample of Norwegian adolescent children (10th grade) and their parents. I match a novel experiment - where parents make real choices for their children — with administrative data on parents' income and education, and children's educational outcomes. In order to explore differences between mothers and fathers, I randomize which parent is invited to participate in the experiment. The experimental data was collected in March and April 2017. The administrative data will be collected in Fall 2017. The pre-analysis plan was submitted to the AEA RCT trial after collection of experimental data, but prior to any data analysis.

This document lays out a plan for the analysis of the experimental data. A document describing the analysis of the administrative data will be appended after the analysis of the experimental data is completed, but prior to the collection of the administrative data.

\section{Sample}

In January 2017, 38 junior high schools in Hordaland, Norway were invited to take part in the research project. Junior high school is compulsory in Norway, and 97\% of children attend public schools. Hordaland is close to the national average in terms of distribution of income, education, and occupations, and includes both the second largest city in Norway as well as less populated rural 
areas. Norway ranked ninth on the United Nations gender inequality index of 2014, yet Norway appears similar to less gender equal societies in that there are large gender differences in competitiveness, women lag men in studying mathematics and science, and the labor market is gendersegregated (both horizontally and vertically) Almås et al., 2015, Birkelund and Sandnes, 2003.

17 schools (16 public and one private) agreed to participate, of which two schools took part in pilot studies, and the remaining 15 constitute the main sample. At each school, two or three 10th grade classes were selected by the school, and in the selected classes all children were invited to participate 1 Participating children had to sign a written consent form together with a parent.

The consent form notifies children and parents that a selected sample of parents will be invited to take part in a related survey, and asks for parents' names and contact information ${ }^{2}$ Then, for each participating child, one parent was randomly chosen, and subsequently contacted by a phone call. In the case that the selected parent could not participate, the other parent was invited in their place.

Both in the recruitment stage and in the design of the experiment, I made extensive efforts to ensure high participation rates from children and parents. To test the representativeness of the sample, I will compare children's grades, and parents' income and educational levels (from administrative data) to national averages.

\section{Experimental Design}

The novel feature of the experiment is to have each parent make a real choice for their child. The choice is if the child will do a task for piece-rate pay or tournament pay, and is a measure of how the parent makes competitiveness choices for their child. Piece-rate pay offers a fixed rate for each correct answer on the task, while tournament pay offers of a higher pay if the child can outperform a randomly selected opponent. The parent's choice has two real consequences. First, the choice may influence the child's earnings. Second, the choice determines if the child has to work in a competitive or non-competitive environment. Importantly, the parent may be able to compensate the child for the earnings in the experiment, but the decision to have the child work in a competitive or non-competitive environment cannot be undone. The child also make the same choice for themselves. As such, the experiment obtains both the parent's competitiveness for the child and the child's own competitiveness. The design builds on the experiment in Niederle and Vesterlund (2007), which has been used in numerous papers to measure competitiveness.

The parent's and the child's choice are independent of each other. In the experiment, the child performs two tasks for which he or she can earn money. At the end of the experiment, one task is randomly selected to determine the child's payout. For one task, the child chooses between piece-rate pay or tournament pay. For the other task, the parent chooses between piece-rate pay or tournament pay for the child.

When making the choice between piece-rate pay and tournament pay, the parent and the child are not aware that the other will be making a similar choice. Importantly, the child is informed of the pay scheme selected by their parent prior to performing the task, but is not told that the choice was

\footnotetext{
${ }^{1}$ I chose to limit the number of participating classes to three per school, in order to avoid having to run experiments on different days at the same school. At two schools, there were only two 10th grade classes, thus only two classes from these schools participated.

${ }^{2}$ Neither parent contact information or parent participation was not required for the child to participate in the research project.
} 
made by the parent. Efforts were to made to present the choice as similarly as possible to parents and children, and both parents' and children's choice are anonymous. The experiment also records a number of background variables from parents and children, including an incentivized measure of a parent's belief about their child's choice.

Experiments were ran in March and April of 2017. At each school, parents and children take part in the experiment on the same day. At 8:00 am parents receive an SMS with a link to the experiment. 3. Parents could can access the experiment on a smartphone or a computer, and the experiment takes about 5 minutes to complete. Parents are asked to finish the experiment by 11:30, after which choices are imputed into the experiment for children. Children participate in the experiment at their school, starting after the school lunch break (typically at noon) and lasting between 30-45 minutes. The classes participated in the experiment sequentially, and I cooperated with teachers to avoid communication between students who had participated in the experiment, and students waiting to participate in the experiment. Since the experiment was ran during school hours, it would be difficult for parents and children to share information about the experiment. Furthermore, parents were also asked in the instructions to not tell their child about their involvement in the experiment (until after the child had completed the experiment).

I now detail the experimental design. The structure of the experiment is illustrated in Figure 1. Instructions for parents and children are found in Appendix A: Parent Instructions and Appendix B: Child Instructions,

\subsection{The Parent's Choice Between Piece-Rate Pay and Tournament Pay}

The parent is first presented with a consent form and a brief introduction to the experiment. The parent then receives information on the task their child will do, and is asked to make a choice between piece-rate pay and tournament pay. The instructions read as follows:

\section{The experiment}

In the experiment your child will do two tasks: Task $A$ and Task B. He/she will be paid for one of the tasks. When the experiment is finished, we will randomly select if he/she is paid for Task $A$ or Task B.

The total payment your child will earn, includes what he/she earns on the task which is selected for payment, in addition to 100 NOK as show-up compensation.

\section{Task A}

In Task A your child will add rows of four two-digit numbers. For example: $21+25+77+64=$ ? $\mathrm{He} /$ she will have three minutes to solve as many of these as possible.

He/she will do the task alone and without a calculator. Teachers and other students will not learn how he/she performs on the task.

\footnotetext{
${ }^{3}$ Some parents informed us that they would not be able to complete the experiment during the day of the experiment. These parents received the SMS at 8;00 pm the night before. Parents could also request to have the link sent by email rather than SMS.
} 


\section{Your child can be paid in two ways for Task $A$.}

1. Piece-rate pay: 5 NOK for each correct answer.

2. Tournament pay: your child will be compared with another student.

- 15 NOK for each correct answer, if your child has more correct answers than the other student.

- 0 NOK for each correct answer, if your child has equally many or fewer correct answers than the other student.

- The other student is randomly drawn from students in a 10th grade class, at another school in Hordaland. The student completed the task for piece-rate pay, and what you choose will not influence the earnings of the other student.

You can now choose if your child will do Task A for piece-rate pay or tournament pay.

- Your choice will not influence how other students are paid.

- Before your child does the task he/she will be told if he/she does the task for piece-rate pay or tournament pay.

- He/she child will not be told that the choice was made by you.

What do you choose for your child?

$$
\text { Piece-rate pay Tournament pay }
$$

\subsection{The Child's Choice Between Piece-Rate Pay and Tournament Pay}

As for the parent, the child is given a brief introduction to the experiment and the task, and is then asked to make a choice between piece-rate pay and tournament pay. In order for the choices of the parent and the child to be comparable, efforts were made to present the information regarding the choice as similarly as possible. The experimental instructions are found in Appendix B: Child Instructions.

\subsection{The Parent's Belief About the Child's Choice}

The experiment elicits an incentivized measure of a parent's belief about their child's choice. The instructions read as follows:

\section{Task B.}

Task B is identical to Task A, but for Task B your child will choose if he/she works for piece-rate pay or tournament pay.

We will now ask you what you think your child will choose. 
- Your child will make his/her choice before learning what he/she will do in Task A.

- Your child will not be told your answer.

\section{Win an iPad Air 2 by guessing correctly.}

As a thank you gift for participating in the survey, three parents will win an iPad. You get one ticket to the iPad lottery for completing the survey. You get three extra tickets to the lottery if you guess correctly what your child will choose.

Will your child choose piece-rate pay or tournament pay?

Piece-rate pay Tournament pay

\subsection{Background Questions}

Below is a list of the background questions that are elicited from parents and children. Instructions are attached in Appendix A: Parent Instructions and Appendix B: Child Instructions.

\section{- Parent:}

- Certainty of choice. After choosing piece-rate pay or tournament pay for their child, the parent indicates on an 11 point scale how certain they are in their choice.

- Certainty of belief. After stating that they believe their child would choose piece-rate pay or tournament pay, the parent indicates on an 11 point scale how certain they are in their belief.

- Belief about performance. The parents indicates on an 11 point scale their belief about their child's relative performance on the task.

- Competitiveness for self. The parent answers if they would choose piece-rate pay or tournament pay for themselves.

- Risk preference quantitative measure. The parent chooses one of five hypothetical lotteries for their child.

- Risk preference qualitative measure. The parent indicates on an 11 point scale their willingness to take risks for their child.

- Belief about importance of competitiveness. The parent indicates on an 11 points scale how important they think competitiveness is for success.

- Belief about importance of success. The parent indicates on an 11 points scale how important they think success is for happiness.

- Belief about gender discrimination. The parent is provided information about the percentage of male CEO's in Norway and indicates on an 11 points scale if they find the shortage of female CEO's problematic.

- Biologically related. Denotes if the parent and the child are biologically related.

- Age. Age of parent.

- Gender. Gender of parent.

- Foreign. Classified by the first name of the parent. 


\section{- Child:}

- Certainty of choice. After choosing piece-rate pay or tournament pay, the child indicates on an 11 point scale how certain they are in their choice.

- Performance on task. The child performs the task three times. 1) For their own choice between piece-rate pay and tournament pay. 2) For their parent's choice between piecerate pay and tournament pay. 3) For tickets to a lottery where they can win one of three iPhone 7. I use performance on 3) as the main measure of performance on task.

- Belief about performance. The child indicates on an 11 point scale their belief about their relative performance on the task.

- Risk preference quantitative measure. The child chooses one of five hypothetical lotteries.

- Risk preference qualitative measure. The child indicates on an 11 point scale their willingness to take risks.

- Competitiveness qualitative measure. The child indicates on an 11 point scale their willingness to compete.

- Belief about importance of competitiveness. The child indicates on an 11 points scale how important they think competitiveness is for success.

- Belief about importance of success. The child indicates on an 11 points scale how important they think success is for happiness.

- Belief about gender discrimination. The child is provided information about the percentage of male CEO's in Norway and indicates on an 11 points scale if they find the shortage of female CEO's problematic

- Job ambitions. The child answers what job they want when they grow up. The answer is coded on a 5 point scale in terms of ambition.

- Belief about father's choice. The child is asked if they believe their father would choose between piece-rate pay and tournament pay for them.

- Belief about mother's choice. The child is asked if they believe their mother would choose between piece-rate pay and tournament pay for them.

- Broken home. Indicates if the child's parents live in the same home.

- Parents married. Indicates if the child's parents are married.

- Number of siblings. Number of siblings of the child.

- Male sibling. Indicates if the child has a male sibling.

- Authoritative parenting style. The child indicates the extent to which their parents 1) take their wishes into consideration, and 2) encourage them to speak their mind.

- Authoritarian parenting style. The child indicates the extent to which their parents 1) punish them by taking privileges away. 2) criticize bad behavior.

- Permissive parenting style. The child indicates the extent to which their parents do not care about their behavior.

- Foreign language. Indicates if the child speaks foreign language at home.

- Gender. Gender of the child.

\subsection{Administrative Data}

I also observe administrative data on parents (income and education) and children (grades, classes choices, choice of vocational or academic high school, and drop out rates). A description of the outcomes in the administrative data will be provided in a document which will be appended to this pre-analysis plan. The document will also describe the analysis of the administrative data. 


\section{Data Analysis}

In this section I specify the project's main research questions and how the research questions will be analyzed. I also note that I anticipate carrying out additional analysis beyond what is included in this document; hence, this document is not intended to be comprehensive or to preclude additional analysis.

\subsection{Interpretation of Data}

A key component of the data analysis is to compare parents' choices for boys to parents' choices for girls. The comparison can be viewed as a descriptive documentation of the difference in how parents make choices of boys and girls. However, the comparison also has a causal interpretation; the effect of child gender on parents' choices. The causal interpretation relies on the assumption that parents choosing for boys, are identical to parents choosing for girls. I now discuss the assumption behind the causal interpretation in more detail. I define:

- $Y$ - a parent's choice of piece-rate pay or tournament pay.

- $T$ - treatment, making a choice for either a boy $(T=0)$ or a girl $(T=1)$.

- $A T$ - assignment to treatment, having either a boy $(A T=0)$ or a girl $(A T=1)$ participating in the research project.

To test the causal effect of child gender on parents' choices, one need to observe in the experiment:

$$
Y(T=1)-Y(T=0)
$$

In contrast, in the experimental data I observe:

$$
\begin{aligned}
& Y(A T=1 \mid T=1)-Y(A T=0 \mid T=0) \\
& \quad=\underbrace{Y(A T=1 \mid T=1)-Y(A T=1 \mid T=0)}_{\text {Causal effect of child gender }}+\underbrace{Y(A T=1 \mid T=0)-Y(A T=0 \mid T=0)}_{\text {Bias }}
\end{aligned}
$$

The "Bias" term in equation (2), reflects that parents making choices for boys and parents making choices for girls, may be different. There are three reasons for why parents may differ:

1) There may be differential selection between boys and girls into the study, which again may cause a selection effect in the comparison of parents of boys and parents of girls. For example, if all boys participate, but only competitive girls participate, the parents' making choices for boys are likely to be different from the parents' making choices for girls. I will test for this type of selection by comparing participation rates of boys and girls.

2) There may be differential selection from parents based on child gender; for example, if all parents making choices for girls are mothers, and all parents making choices for boys are fathers. I will test for selection by producing a balance by child gender with participation rate for mothers, participation rate for fathers, age (parents) and whether the parent and the child are biologically related.

3) Having a male or female child may shape the parent. That is, raising a female or male child may influence how the parent make choices. I have two tests to explore if the gender of the child shapes parents. 
1. I compare the sample of parents with children only of the same gender, to the sample of parents with children of both genders. If child gender shapes parents, then there should be a smaller difference between the choices of parents of boys and parents of girls for the parents who have both daughters and sons, than for parents who only have daughters or only have sons.

2. I test if parents of boys and parents of girls have different attitudes towards competitiveness, success in the labor market, and shortage of female CEO's in Norway.

If there is no differences between the samples on these tests, it would suggest that parents are not strongly influenced by the gender of the child.

\subsection{Child Data}

My primary objective in analyzing the child data is to test if there is a difference between the competitiveness choices made by boys and girls. In the literature, the typical finding is that boys choose tournament pay much more frequently than girls (see Niederle, 2014 for a review).

Research question 1 Do boys choose tournament pay more often than girls?

I test the research question using the following specification:

$$
c_{i}=\alpha_{0}+\alpha_{1} g_{i}+\mathbf{A}^{\mathbf{T}} \mathbf{X}_{\mathbf{i}}+s_{k(i)}+\epsilon_{i}
$$

where

- $c_{i}$ - an indicator variable equal to 1 , if child $i$ chose tournament pay.

- $g_{i}$ - an indicator variable equal to 1 , if child $i$ is female.

- $\mathbf{X}_{\mathbf{i}}$ - is a set of controls. I run the specification with and without controls.

- Belief about performance on task (child).

- Performance on task (child).

- Risk preferences qualitative measure (child).

- Risk preferences quantitative measure (child).

- $s_{k(i)}$ - denotes a school fixed effect. I run the specification with and without the school fixed effect.

- $\epsilon_{i}$ - an individual-level error term. The specification uses robust standard errors.

The estimated coefficient on $\alpha_{1}$ addresses research question 1 , where $\alpha_{1}<0$ is evidence for boys choosing more tournament pay than girls. The inclusion of additional control variables allows me to further explore if the result is robust to controlling for other attributes. Moreover, I also plan test if there are earning differences between boys and girls, which would speak to the question of whether boys or girls make better decisions in this environment. 


\subsection{Parent Data}

The parent data allows me to address questions that have not yet been studied in the literature. I first consider whether parents choose differently for boys and girls.

Research question 2 Do parents choose tournament pay more often for boys than for girls?

To test research question 2 , I use the following specification:

$$
c_{i}=\alpha_{0}+\alpha_{1} g_{i}+\mathbf{A}^{\mathbf{T}} \mathbf{X}_{\mathbf{i}}+s_{k(i)}+\epsilon_{i}
$$

where

- $c_{i}$ - an indicator variable equal to 1 , if parent $i$ chose tournament pay for their child.

- $g_{i}$ - an indicator variable equal to 1 , if the child which parent $i$ is making a choice for is female.

- $\mathbf{X}_{\mathbf{i}}$ - is a set of controls. I run the specification with and without controls.

- Age (parent).

- Biologically related to child (parent).

- Foreign (parent).

- Gender (parent).

- $s_{k(i)}$ - denotes a school fixed effect. I run the specification with and without the school fixed effect.

- $\epsilon_{i}$ - an individual-level error term. The specification uses robust standard errors.

The estimated coefficient on $\alpha_{1}$ provides evidence on the extent to which parents choose differently for boys and girls. I also test if there are differences in the choices made by mothers and fathers, by running 4 and interacting child gender with parent gender. The comparison of mothers and fathers is of first order interest to the research project, and a key feature of the design was to randomly invite mothers or fathers to participate.

I next turn my attention to factors that may explain parents' choices beyond child gender.

Research question 3 What explain parents' choices?

To shed further light on research question 3, I run 4 and add control variables that may be relevant for parents' choices. I focus on variables related to either parents' beliefs about their children, or parents own preferences for competitiveness and risk taking. The variables are:

- Belief about choice (parents).

- Belief about performance (parents).

- Risk preference qualitative measure (parents).

- Risk preference quantitative measure (parents).

- Preference for competitiveness for self (parents). 
The specification sheds light on several interesting questions; for example, are parents' choices primarily motivated by choosing what they believe the child prefers, or are choices also driven by other considerations? I also run the specification separately for i) boys and girls, to test if different factors drive choices for boys and girls, and ii) mothers and fathers, to explore if mothers and fathers make decisions based on different factors.

\subsection{Combining Parent and Child Data}

I now take advantage of the fact that I have unique data on both children and parents. I combine the data in two ways, 1) comparing children's and parents' choices in aggregate, and 2) comparing parents and the children within the parent-child-pair.

\subsubsection{Children's and Parents' Choices in Aggregate}

I compare children's and parents' choices to see in which scenario the gender difference in selection into tournament pay is larger.

Research question 4 Is the gender differences in selection into tournament pay larger when parents choose?

To test the research question, I merge the data on parents' and children' choices and run the following specification:

$$
c_{i}=\alpha_{0}+\alpha_{1} g_{i}+\alpha_{2} p_{i}+\alpha_{3} p_{i} * g_{i}+\mathbf{A}^{\mathbf{T}} \mathbf{X}_{\mathbf{i}}+s_{k(i)}+\epsilon_{i}
$$

where

- $c_{i}$ - an indicator variable equal to 1 if either 1) $i$ is a child, and $i$ chose tournament pay, or 2) $i$ is a parent, and $i$ chose tournament pay for their child.

- $g_{i}$ - an indicator variable equal to 1 if either 1) $i$ is a child, and $i$ is female, or 2) $i$ is a parent, and the child which $i$ chose for is female.

- $p_{i}$ - an indicator variable equal to 1 if $i$ is a parent.

- $\mathbf{X}_{\mathbf{i}}$ - is a set of controls. I run the specification with and without controls.

- Age (parent).

- Biologically related to child (parent).

- Foreign (parent).

- Gender (parent).

- $s_{k(i)}$ - denotes a school fixed effect. I run the specification with and without the school fixed effect.

- $\epsilon_{i}$ - an individual-level error term. The specification uses robust standard errors.

The estimated coefficient on $\alpha_{3}$ provides evidence on the gender difference in parents' choices relative to children's choices. I also test if gender differences in earnings are larger when parents are choosing, or when children are choosing.

I run all the above specifications separately for mothers and father to test for heterogeneity. 


\subsubsection{Children' and Parents' Within the Parent-Child-Pair}

I ask if there is more disagreement - which I define as the parent and child in a parent-child-pair choosing differently between piece-rate pay and tournament pay - between parents and boys, or parents and girls.

Research question 5 Do parents disagree more with boys or girls?

To test research question 4, I run the following specification:

$$
d_{j}=\alpha_{0}+\alpha_{1} g_{j}+\mathbf{A}^{\mathbf{T}} \mathbf{X}_{\mathbf{j}}+s_{k(J)}+\epsilon_{j}
$$

where

- $d_{j}$ - an indicator variable equal to 1 , if the parent and child in parent-child-pair $j$ chose differently. That is, either i) the parent chose tournament pay for the child, and the child chose piece-rate pay. Or, ii) the parent chose piece-rate pay for the child, and the child chose tournament pay.

- $g_{j}$ - an indicator variable equal to 1 , if the child in parent-child-pair $j$ is female.

- $\mathbf{X}_{\mathbf{j}}$ - is a set of controls. I run the specification with and without controls.

- Age (parent).

- Biologically related to child (parent).

- Competitiveness choice (child).

- Foreign (parent).

- Gender (parent).

- $s_{k(j)}$ - denotes a school fixed effect. I run the specification with and without the school fixed effect.

- $\epsilon_{j}$ - an parent-child pair-level error term. The specification uses robust standard errors.

The estimated coefficient on $\alpha_{1}$ tells us if there is more disagreement between parents and boys, or parents and girls. I also run 6 where I interact parent gender with child gender, to test for heterogeneity between mothers and fathers.

\subsection{Exploratory Research Questions}

In the paper, an online appendix or follow up papers, I will also explore the following research questions:

- Do fathers choose tournament pay for themselves more often than mothers choose tournament pay for themselves?

- Children's beliefs about parents' choices:

- Do children believe their fathers will choose tournament pay for them more often than children believe their mothers will choose tournament pay for them?

- Do boys believe their parents will choose tournament pay for them more often than girls believe their parents will choose tournament pay for them? 
- Do boys believe their fathers will choose tournament pay for them more often than girls believe their fathers will choose tournament pay for them?

- Do boys believe their mothers will choose tournament pay for them more often than girls believe their mothers will choose tournament pay for them?

- To what extent are parents' competitiveness choices for themselves correlated with children's competitiveness choices?

- Is the difference in parents' choices for boys and girls smaller or larger than the gender difference in parents' competitiveness choices for themselves?

- Is the difference in parents' choices for boys and girls smaller or larger than the difference between boys' and girls' beliefs about parents' choices?

- Accuracy of parents' beliefs:

- Do parents have more accurate beliefs about boys or girls?

- Do fathers or mothers have more accurate beliefs?

- Do parents who claim to be more certain about their beliefs, have more accurate beliefs?

- Are parents' beliefs biased towards their own preference for piece-rate pay or tournament pay (for themselves)?

\subsection{Administrative Data}

I will append a document describing in detail the analysis of the administrative data. I have two main goals with the administrative data:

1. Explore how parents' and children's choices predict children's educational outcomes. Prior research have documented that children's competitiveness choices are an important predictor of educational choices [Zhang, 2013, Buser et al., 2014]. This will be the first study to explore the role of parents' competitiveness choices for their children.

2. Explore heterogeneity in parent's and children' choices along socioeconomic status. Prior research finds that socioeconomic status is an important predictor for gender differences in competitiveness Almås et al., 2015.

\section{References}

[Almås et al., 2015] Almås, I., Cappelen, A. W., Salvanes, K. G., Sørensen, E. Ø., and Tungodden, B. (2015). Willingness to compete: Family matters. Management Science.

[Birkelund and Sandnes, 2003] Birkelund, G. E. and Sandnes, T. (2003). Paradoxes of welfare states and equal opportunities: Gender and managerial power in norway and the usa. Comparative Social Research, 21:203-242.

[Buser et al., 2014] Buser, T., Niederle, M., and Oosterbeek, H. (2014). Gender, competitiveness, and career choices. Quarterly Journal of Economics, 129(3).

[Dohmen et al., 2011] Dohmen, T., Falk, A., Huffman, D., and Sunde, U. (2011). The intergenerational transmission of risk and trust attitudes. The Review of Economic Studies, page rdr027.

[Fagereng et al., 2015] Fagereng, A., Mogstad, M., and Rønning, M. (2015). Why do wealthy parents have wealthy children? Available at SSRN. 
[Heckman, 2014] Heckman, J. J. (2014). Going forward wisely. white house summit on early education. Washington, DC. Available at: $h$ ttp://heckmanequation. org/content/white-housesummit-earlyeducation\# disqus_thread.

[Knudsen et al., 2006] Knudsen, E. I., Heckman, J. J., Cameron, J. L., and Shonkoff, J. P. (2006). Economic, neurobiological, and behavioral perspectives on building americas future workforce. Proceedings of the National Academy of Sciences, 103(27):10155-10162.

[Niederle, 2014] Niederle, M. (2014). Gender. Forthcoming in Handbook of Experimental Economics.

[Niederle and Vesterlund, 2007] Niederle, M. and Vesterlund, L. (2007). Do women shy away from competition? do men compete too much? Quarterly Journal of Economics, pages 1067-1101.

[Sacerdote, 2007] Sacerdote, B. (2007). How large are the effects from changes in family environment? a study of korean american adoptees. The Quarterly Journal of Economics, pages $119-157$.

[Sacerdote, 2010] Sacerdote, B. (2010). Nature and nurture effects on childrens outcomes: What have we learned from studies of twins and adoptees. Handbook of social economics, 1:1-30.

[Zhang, 2013] Zhang, Y. J. (2013). Can experimental economics explain competitive behavior outside the lab? Available at SSRN 2292929. 
Figure 1: Set-up Experiment

\section{Parents:}

Receive SMS at 8:00 am with link to experiment.

Introduction to experiment.

Choice: will your child work for piece-rate pay or tournament pay?

Belief elicitation: will your child choose piece-rate pay and tournament pay?

Background questions.

\section{Children:}

Experiments starts at 12:00 pm at school.

Introduction

Choice: do you want to work for piece-rate pay or tournament pay?

Task 1: work for own choice.

Task 2: work for parents' choice.

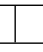

Background questions.

Payment: task 1 or task 2 is randomly selected to determine children's payment. 


\section{Appendix A: Parent Instructions}

The instructions have been translated from Norwegian. For original instructions in Norwegian, email jonas.tungodden@gmail.com. Notes are in italic.

\section{Welcome!}

Thank you for participating! This survey takes about 5 minutes and is related to the experiment your child and his/her classmates will take part in later today.

We ask that you complete the survey alone, and that you do not talk with your child about the survey (until after he/she has finished the experiment). This is very important for our research.

If you need help with the survey or have other questions, you can contact us on the telephone number listed at the bottom of every page.

Below follows a consent form for participating in this research project. Click on the arrow to accept it and start the survey.

\section{Consent to participate in research}

Participation in research is completely voluntary and you are free to stop taking part in the project at any time. If you agree to participate we ask you to complete the following survey. Your answers will be linked with de-identified data on education and income from Statistics Norway. That data is de-identified means that all information which can identify you has been replaced with a key code which refers to a different file which contains personal information. As with all research, there is a chance that confidentiality could be compromised; however, we are taking precautions to minimize this risk. The file with personal information will be stored on a server with two factor identification in an encrypted file. No researchers will have access to this file, and if the results from the study is published or presented, no personal information will be used.

If you have any questions about this research, please feel free to contact us, either by phone 4795 8527 or jonast@berkeley.edu.

For questions about the survey:

47958527

Page break

\section{The experiment}

In the experiment your child will do two tasks: Task A and Task B. He/she will be paid for one of the tasks. When the experiment is finished, we will randomly select if he/she is paid for Task A or Task B. 
The total payment your child will earn, includes what he/she earns on the task which is selected for payment, in addition to $100 \mathrm{NOK}$ as show-up compensation.

For questions about the survey:

47958527

\section{Page break}

\section{Task A}

In Task A your child will add rows of four two-digit numbers. For example: $21+25+77+64=$ ? $\mathrm{He} / \mathrm{she}$ will have three minutes to solve as many of these as possible.

$\mathrm{He} /$ she will do the task alone and without a calculator. Teachers and other students will not learn how he/she performs on the task.

\section{Your child can be paid in two ways for Task A.}

1. Piece-rate pay: 5 NOK for each correct answer.

2. Tournament pay: your child will be compared with another student.

- 15 NOK for each correct answer, if your child has more correct answers than the other student.

- 0 NOK for each correct answer, if your child has equally many or fewer correct answers than the other student.

- The other student is randomly drawn from students in a 10th grade class, at another school in Hordaland. The student completed the task for piece-rate pay, and what you choose will not influence the earnings of the other student.

\section{You can now choose if your child will do Task A for piece-rate pay or tournament pay.}

- Your choice will not influence how other students are paid.

- Before your child does the task he/she will be told if he/she does the task for piece-rate pay or tournament pay.

- He/she child will not be told that the choice was made by you.

What do you choose for your child?

$$
\text { Piece-rate pay Tournament pay }
$$

For questions about the survey:

47958527 


\title{
How certain were you in your choice?
}

- 0 = very uncertain. I could just as well have chosen piece-rate pay (tournament pay - if parent chose piece-rate pay).

- 10 = completely certain. I could never have chosen piece-rate pay (tournament pay - if parent chose piece-rate pay).

\begin{tabular}{ccccccccccc}
0 & 1 & 2 & 3 & 4 & 5 & 6 & 7 & 8 & 9 & 10 \\
Not uncertain & \multicolumn{5}{c}{ Very certain }
\end{tabular}

For questions about the survey:

47958527

Page break

\section{Task B.}

Task B is identical to Task A, but for Task B your child will choose if he/she works for piece-rate pay or tournament pay.

We will now ask you what you think your child will choose.

- Your child will make his/her choice before learning what he/she will do in Task A.

- Your child will not be told your answer.

\section{Win an iPad Air 2 by guessing correctly.}

As a thank you gift for participating in the survey, three parents will win an iPad. You get one ticket to the iPad lottery for completing the survey. You get three extra tickets to the lottery if you guess correctly what your child will choose.

\section{Will your child choose piece-rate pay or tournament pay?}

\author{
Piece-rate pay Tournament pay
}

For questions about the survey:

47958527 


\section{How certain were you in your answer?}

- 0 = very uncertain. My child could just as well have chosen piece-rate pay (tournament pay - if parent guessed piece-rate pay).

- 10 = completely certain. My child could never have chosen piece-rate pay (tournament pay - if parent guessed piece-rate pay).

\begin{tabular}{lcccccccccc}
0 & 1 & 2 & 3 & 4 & 5 & 6 & 7 & 8 & 9 & 10 \\
Not uncertain & \multicolumn{6}{c}{ Very certain }
\end{tabular}

For questions about the survey:

47958527

\section{Page break}

How well do you think your child will perform on the task relative to other students in Hordaland?

- $0=$ among the $10 \%$ worst on the task.

- $50=$ in the middle.

- $100=$ among the $10 \%$ best on the task.

$\begin{array}{lllllllllll}0 & 1 & 2 & 3 & 4 & 5 & 6 & 7 & 8 & 9 & 10 \\ \text { Poorly } & & & \\ \text { Very well } & \end{array}$

For questions about the survey:

47958527

Page break

Would you choose piece-rate pay or tournament pay for yourself?

(If you participated in the experiment together with other parents from the class.)

Piece-rate pay Tournament pay 
If you could give your child one of the following bonuses as an extra payment in the experiment: which would you choose? (This is a hypothetical question, meaning, the bonus will not actually be paid to you child.)

- $200 \mathrm{NOK}$

- 350 NOK with $50 \%$ probability, 50 NOK with $50 \%$ probability

- 400 NOK with $50 \%$ probability, 100 NOK with $50 \%$ probability

- 500 NOK with $50 \%$ probability, 50 NOK with $50 \%$ probability

- 600 NOK with $50 \%$ probability, 0 NOK with $50 \%$ probability

When you make a choice for your child (the one participating in the experiment), are you generally willing to take risk, if there also is a possibility for a gain?

\begin{tabular}{lllllllllll}
0 & 1 & 2 & 3 & 4 & 5 & 6 & 7 & 8 & 9 & 10 \\
\multicolumn{3}{l}{ Not willing } & \multicolumn{4}{c}{ Very willing }
\end{tabular}

Do you think it is important to be competitive in order to be successful in today's society?

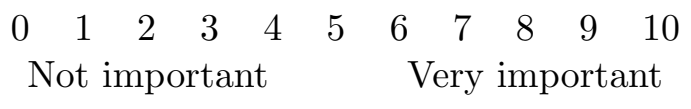

How important do you think it is to be successful in order to be happy?

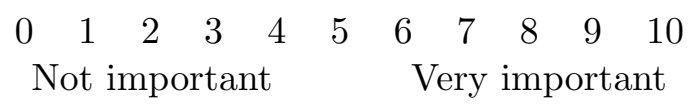

$84 \%$ of Norwegian stock based companies have male CEOs. To what degree do you think this is a problem for our society?

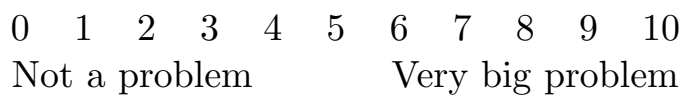

Are you the biological father or mother of the child in the experiment?

Yes $\quad$ No


Do you live in the same house as the child in the experiment?

Yes No

What is your age?

For questions about the survey:

47958527

Page break

\section{Thank you for your participation!}

Your participation is very important for our research project and we are very thankful for your time.

We hope that you can help us further by not talking to your child about the survey, until he/she has finished the experiment.

We will contact the winners of iPad Air 2 after we have completed the survey at all the schools participating in the research project.

Please contact us at 47958527 or jonast@berkeley.edu, if you have any questions related to the survey or the research project. 


\section{Appendix B: Child Instructions}

The instructions have been translated from Norwegian. For original instructions in Norwegian, email jonas.tungodden@gmail.com. Notes are in italic.

\section{Welcome to the experiment!}

Thank you for participating! The experiment takes about 30 minutes.

Enter you experiment code and press "next" to start the experiment.

Page break

\section{The experiment}

In the experiment you will do two tasks: Task A and Task B. You will be paid for one of the tasks. When the experiment is finished, we will randomly select if you are paid for Task A or Task B.

The total payment you will earn includes what you earn on the task which is selected for payment, in addition to $100 \mathrm{NOK}$ as show-up compensation.

Page break

\section{Task A.}

In Task A you will be asked to sum four two-digit numbers. For example: $21+25+77+64=$ ? You have three minutes to solve as many questions as possible. You will do the task alone and without a calculator. Teachers and others students will not learn how well you performed on the task.

\section{You can be paid in two ways for Task A.}

1. Piece-rate pay: 5 NOK for each correct answer.

2. Tournament pay: you will be compared with another student.

- 15 NOK for each correct answer, if you have more correct answers than the other student.

- 0 NOK for each correct answer, if you have fewer or equally many correct answers as the other student. 
- The other student is a randomly selected tenth grade student at another school in Hordaland, where the task was done for piece-rate pay. What you choose will not influence the payment to the other student.

\section{What do you choose?}

\section{Piece-rate pay Tournament pay}

\section{Page break}

\section{How certain were you in your choice?}

- 0 = very uncertain. I could just as well have chosen piece-rate pay (tournament pay - if the child chose piece-rate pay).

- 10 = very certain. I could never have chosen piece-rate pay (tournament pay - if the child chose piece-rate pay).

\begin{tabular}{ccccccccccc}
0 & 1 & 2 & 3 & 4 & 5 & 6 & 7 & 8 & 9 & 10 \\
Not uncertain & \multicolumn{4}{c}{ Very certain }
\end{tabular}

Page break

Task A will start when you press "Next". You will then have 3 minutes to solve the questions.

$$
\text { Page break }
$$

Time left: 180

$$
73+58+90+23=?
$$

Next question 
Page break

You are now finished with Task A.

Press "Next" to go to Task B.

Page break

Task B is identical to Task A, but in Task B you will not get to decide for yourself if you will do the task for piece-rate pay or tournament pay. Instead, the choice will be made either by a random draw or by another participant in the research project.

Page break

The following text was shown if piece-rate pay was chosen by the parent (or by random draw, in the case were the parent failed to answer the parent experiment in time):

You will do Task B for piece-rate pay. That means you will get 5 NOK for each correct answer.

Press "Next" to start Task B. You will then have 3 minutes to solve the questions.

The following text was shown if tournament pay was chosen by the parent (or by random draw, in the case were the parent failed to answer the parent experiment in time):

You will do Task B for tournament pay. That means:

- 15 NOK for each correct answer, if you have more correct answers than the other student.

- $0 \mathrm{NOK}$ for each correct answer, if you have fewer or equally many correct answers as the other student.

- The other student is a randomly selected tenth grade student at another school in Hordaland, where the task was done for piece-rate pay. What you choose will not influence the payment to the other student.

Press "Next" to start Task B. You will then have 3 minutes to solve the questions.

Page break 
Time left: 180

$$
43+68+86+15=?
$$

Next question

\section{Page break}

\section{You have now completed Task A and Task B.}

You will now do a Bonus Task. The Bonus Task is the same as Task A and Task B, but you now have the opportunity to earn tickets to an iPhone lottery.

Three iPhone 7 Plus will be won by students who are participating at this experiment or the same experiment at other schools. All students participating in the experiment receives 1 ticket to the iPhone lottery. You will also receive one extra ticket for each correct answer in the Bonus Task.

Press "Next" to start the Bonus Task. You will then have 3 minutes to solve the questions.

\section{Page break}

Time left: 180

$$
54+12+36+64=?
$$

Next question

Page break

You are now finished with all the tasks. 
How well do you think you performed on the task relative to other students in Hordaland?

- $0=$ among the $10 \%$ worst on the task.

- $50=$ in the middle.

- $100=$ among the $10 \%$ best on the task.

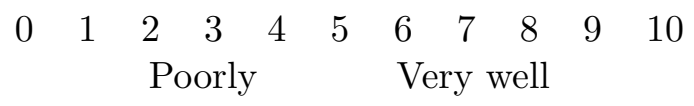

Page break

If you could get one of the following bonuses as an extra payment in the experiment: which would you choose? (This is a hypothetical question, meaning, the bonus will not actually be paid to you).

- $200 \mathrm{NOK}$

- 350 NOK with $50 \%$ probability, 50 NOK with $50 \%$ probability

- 400 NOK with $50 \%$ probability, 100 NOK with $50 \%$ probability

- 500 NOK with $50 \%$ probability, 50 NOK with $50 \%$ probability

- 600 NOK with $50 \%$ probability, 0 NOK with $50 \%$ probability

Page break

How do you think about yourself? Are you are person who is generally willing to take risk, or do you try to avoid risk. Answer on a scale from 0 to 10, where 0 means "not willing to take risk at all", and 10 means "very willing to take risk".

$$
\begin{array}{lllllllllll}
0 & 1 & 2 & 3 & 4 & 5 & 6 & 7 & 8 & 9 & 10
\end{array}
$$

How willing do you think you are to compete? Answer on a scale from 0 to 10, where 0 means "not willing to compete", and 10 means "very willing to compete".

$\begin{array}{lllllllllll}0 & 1 & 2 & 3 & 4 & 5 & 6 & 7 & 8 & 9 & 10\end{array}$


Do you think it is important to be competitive in order to be successful in today's society?

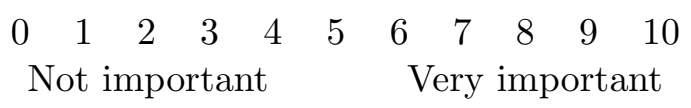

How important do you think it is to be successful in order to be happy?

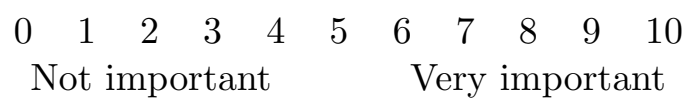

$84 \%$ of Norwegian stock based companies have male CEOs. To what degree do you think this is a problem for our society?

$\begin{array}{lllllllllll}0 & 1 & 2 & 3 & 4 & 5 & 6 & 7 & 8 & 9 & 10\end{array}$

Not a problem Very big problem

Page break

What job do you want when you grow up?

Page break

If your mother were to choose between piece-rate pay and tournament pay for you, what do you think she would choose?

$$
\text { Piece-rate pay Tournament pay }
$$

If your father were to choose between piece-rate pay and tournament pay for you, what do you think he would choose? 
Piece-rate pay Tournament pay

Page break

Does your parents live together?

Yes No

Are your parents married to each other?

Yes No

Page break

How many older sisters do you have?

How many younger sisters do you have?

How many older brothers do you have?

How many younger brothers do you have?

Page break

On a scale from 1 to 6 , indicate how accurately does the following statements describe your parents. Where $1=$ "does not at all describe my parents" and $6=$ "very well describes my parents".

- My parents take my wishes into consideration before they ask me to do something. $\begin{array}{llllll}1 & 2 & 3 & 4 & 5 & 6\end{array}$

- My parents encourage me to speak my mind even if they disagree. $\begin{array}{llllll}1 & 2 & 3 & 4 & 5 & 6\end{array}$

- My parents punish me by taking privileges away from me (e.g. TV, games, visiting friends). $\begin{array}{llllll}1 & 2 & 3 & 4 & 5 & 6\end{array}$ 
- My parents criticize me when my behavior does not meet their expectations. $\begin{array}{llllll}1 & 2 & 3 & 4 & 5 & 6\end{array}$

- My parents do not care about my behavior.

$\begin{array}{llllll}1 & 2 & 3 & 4 & 5 & 6\end{array}$

\section{Page break}

Your gender:

- Male

- Female

Do you speak another language than Norwegian at home?

- Yes.

- No.

Page break

We now draw if you will be paid for Task A or Task B.

Please wait.

\section{Page break}

\section{Payment.}

On Task A you had ? correct answers.

On Task B you had ? correct answers.

On the bonus task you had ? correct answers.

The task which will determine your payment is ?.

On the task you earned? NOK. In addition you get 100 NOK a show-up payment. In total you have earned ?.

We will contact the winners of the iPhone lottery in May, after we have completed the experiment at all the schools that participated in the research project. 